University for Business and Technology in Kosovo

UBT Knowledge Center

Nov 7th, 9:00 AM - 5:00 PM

\title{
Internet of Things: From applications, challenges and standardization to Industry implementations
}

Xhafer Krasniqi

University for Business and Technology, xhafer.krasniqi@emea.nec.com

Follow this and additional works at: https://knowledgecenter.ubt-uni.net/conference

Part of the Computer Sciences Commons, and the Digital Communications and Networking Commons

\section{Recommended Citation}

Krasniqi, Xhafer, "Internet of Things: From applications, challenges and standardization to Industry implementations" (2015). UBT International Conference. 104.

https://knowledgecenter.ubt-uni.net/conference/2015/all-events/104

This Event is brought to you for free and open access by the Publication and Journals at UBT Knowledge Center. It has been accepted for inclusion in UBT International Conference by an authorized administrator of UBT Knowledge Center. For more information, please contact knowledge.center@ubt-uni.net. 


\title{
Internet of Things: From applications, challenges and standardization to Industry implementations
}

\author{
Xhafer Krasniqi \\ UBT-Higher Education Institution \\ NEC Corporation \\ xhafer.krasniqi@emea.nec.com
}

\begin{abstract}
The Internet of Things that is defined as anything that can be accessible anytime and anywhere provides connectivity to different objects and sensors around us and which will enable the transfer of different data between these objects and devices. A thing in the Internet of Things can be any natural or man-made object that can be assigned an IP address with a capability to exchange date over a network. There is a huge number of applications of IoT to benefit users, such as health monitors, smart homes, connected cars etc.

If everything around us is connected and information about these things that can contain sensitive information, e.g. health and other personal information, are collected then these networks become very important and must be able to provide a proper security and privacy. It is believed that by 2020 there will be over 50 billion things that could be connected to Internet.

Internet of things are very much associated with M2M (machine to machine communication) that is identified as a technology that makes objects smart, like smart homes, smart utility meters etc. M2M actually is considered to be a subset of IoT and which is mainly used for difficult and dangerous tasks, e.g. nuclear plants, etc. The deployment of IoT has already started and is expected to transform the way we live. According to Gartner, a technology research company, the Internet of Things has just reached the deployment stage by early adopters and the full deployment is expected in over ten years. From an industry angle, this paper will examine the market and technical trends of Internet of Things, main applications that will be supported by this technology, key issues and challenges faced by the industry, standards activities around IoT and finally the implementation landscape.
\end{abstract}

Keywords: Internet of Things, M2M, nuclear plants, tasks.

\section{Introduction}

The idea of connecting everything existed for quite some time, since early 2000 , but the technology to support this connectivity and other supporting factors were not available then. The idea came from the need to have computers manage all things in daily life, those inanimate and living things, that could be equipped with identifiers and wireless connectivity, and which could communicate with each other. Although we do not have a clear definition of IoT yet, probably the best definition of IoT that the industry has come up with is that the IoT is the disruptive convergence of technology, telecommunications, data, and people as reflected in the figure below. So, IoT is a system of enabling technologies and not a specific set of technologies. 


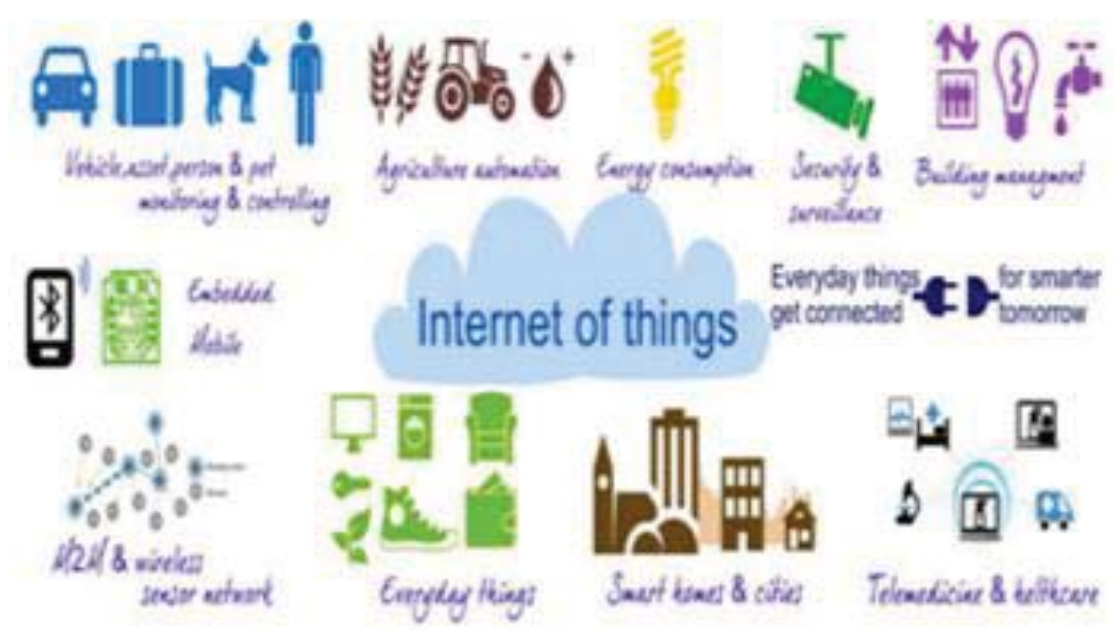

Fig. 1. Internet of Things (Source: datascience.com)

Back in 2000 we did not have enough addresses for all those devices, we did not have good mobile data coverage, mobile service was extremely expensive and the battery technology was not able to power up and support all these objects. The situation with those factors has changed drastically in the meantime and the prices have fallen rapidly as shown in figure 2.

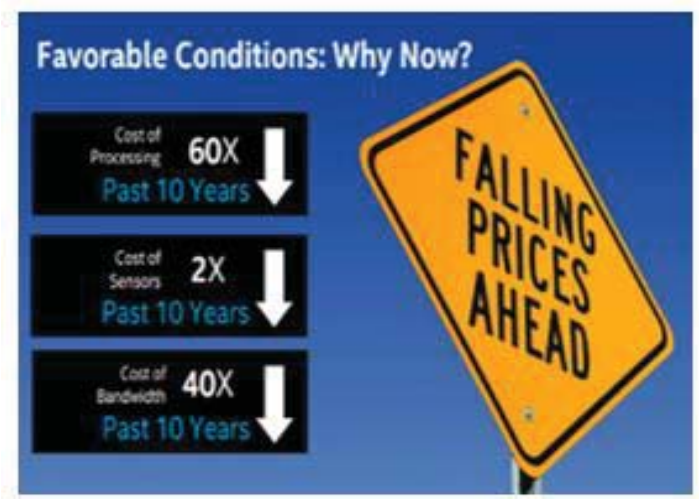

Fig. 2. Relevance of price falling

Resulting from these condition changes, the industry is thinking and getting seriously involved in developing and implementing the IoT. It is believed that by 2020 there will be over 50 billion things that could be connected to Internet. To speed up and achieve the full deployment the industry still needs to see the innovative IoT solutions from vendors and others involved which would enhance the customer experience and improve the operating efficiency. We also need to develop common standards to enable communication and interaction between different products and different solutions from different vendors and players and above all we also need close collaboration between the industry stakeholders to achieve this full deployment.

This paper focuses on the vertical markets of IoT, applications and drivers of this technology, then technical and market trends, challenges and issues faced by the industry, standards around IoT and finally use cases and implementation landscape. 
International Conference on Computer Science and Communication Engineering, Nov 2015

\section{IoT Vertical Markets}

Given that IoT applies to a wide range of markets, it is important to identify those markets in order to better categorise the applications and to better understand their functions. Main vertical markets where IoT technology and IoT applications are having a huge impact are the following:

- Computing industry

○ Human behaviour towards internet connected devices can change by installing sensors in computing devices to mimic our senses

- Health industry

- Nano-sensors will be included in the medicine that the patient is taking and doctors can monitor the effect of it on the patient in real-time

- It is anticipated that by 2020 patients will not have to go to a doctor for a doctor to know how the patients are doing, as the doctor receive all information from the sensors the patient is wearing [2]

- Environment

- Sensors will be placed around the work to improve the response time to earthquakes

○ To help find more oil in different corners of the world

- Household

○ IoT enhances home automation system to integrate electrical devices in a house with each other and gives the users the possibility to access those devices via smartphones or tablets

- Automotive

○ Sensors have found and are finding wide application in transportation industry to monitor driver behaviours, to optimize routing and fuel consumption

- $\quad$ Retail market

- This is another vertical market where RFID tags are being installed widely to improve the efficiency of checking out of items which do not have to be put on the conveyer belt to be scanned, but they can be scanned automatically by leaving the supermarket

\section{Main Applications And Drivers Of IoT}

The list of applications where IoT can be applied and used is huge since trillions of sensors will comprise the IoT. This will drive to 50 zettabytes of data annually by 2020 and which will be an enormous task to collect and analyse [2].

For today's Internet humans are the main creators of data, e.g. people write documents, build databases, photograph and upload images, but by 2020 we will see almost the exact opposite, as hundreds of millions of Internet-connected devices primarily use information that originates from other devices and not from humans. This is also known as machine-to-machine (M2M) communications, a subset of IoT and fast-growing portion of the embedded systems market.

The list of applications and drivers can be categorized in few groups based on the use and the markets that push for full deployment. This list can serve as a subgroup of IoT vertical markets, but it is more granular and function-specific:

- $\quad$ Tracking for the purpose of advertising and marketing

- Helps advertisers and marketers to make creative campaigns by tracking consumers and their behaviour

- $\quad$ Enhanced context awareness

- Enables a capability to sense their physical environment, and adapt their behaviour accordingly

- $\quad$ Process and business optimization

- IoT is widely accepted as a technology that would help to optimize processes and businesses 
- Business transformation

- IoT will transform businesses and improve their operation cost

- Optimization of resource consumption

- Enhances resource consumption, e.g. fuel consumption in the automotive systems

- Enhanced control in autonomous systems

- Improvement of automation process through data analysis collected by IoT sensors

- Ubiquitous networking

○ Allows program applications to follow a user through IoT special sensors wherever he/she would go

- Connected computing

○ Our behaviour recording through all our connected devices

- Ubiquitous sensors

- Low sensor prices is considered to be an important driver

- Prices will move from $\$ 0.09$ to $\$ 0.03$ for passive sensors and from $\$ 1$ to $\$ 0.15$ for active sensors respectively by 2021[2]

- These low prices of sensors can lead to widespread deployment of sensors in all types of devices and all types of industries

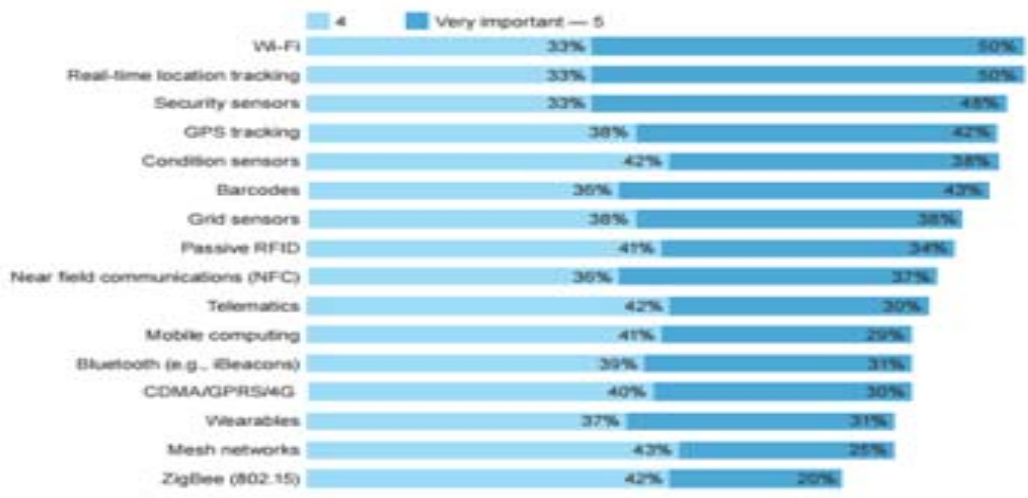

Fig. 3. Individual technologies vs. IoT (Source: Forrester Consulting, Nov. 2014)

\section{IoT Market And Technology Trends}

As predicted there is a huge potential for IoT and the industry's expectation is shown in figure 4, where IoT is one of the biggest technology waves since 1960s. Internet of things is considered to be the third wave of Internet after the first wave that brought common software applications like Microsoft Windows and Google and second wave that enabled transition to mobile software such as iOS and Android that enabled large number of devices to easily communicate. 




Fig. 4. IoT as a big technology wave (Source: KPCB, ITU, MS Research)

According to Gartner, a technology research company, the Internet of Things has just reached the deployment stage by early adopters as it was the case with Cloud computing in 2008-2010 and with Big Data analytics in 2011-2013 and the full deployment is expected in over ten years [1].

Gartner also predicts that the aggregated value and economic benefit of the IoT will exceed \$1.9 trillion in the year 2020 alone [3]. On the other side, McKinsey Global Institute, another business and economics research firm, predicts that IoT global economic benefits to be up to $\$ 11$ trillion in 2025 and business-to-business applications will account for $70 \%$ of the revenue [4].

Growth trend and forecast for connected devices is shown in figure 5, where Internet of things occupies a big chunk of the market [8].



Fig. 5. Growth and forecast for connected devices

Increasing interest for IoT development increases the demand for lots of IoT developers as shown in figure 6 [1]. Developers are the main force behind IoT and it is believed that $17 \%$ of the world developers are already working on IoT applications, in particular those in Asia-Pac [3]. 


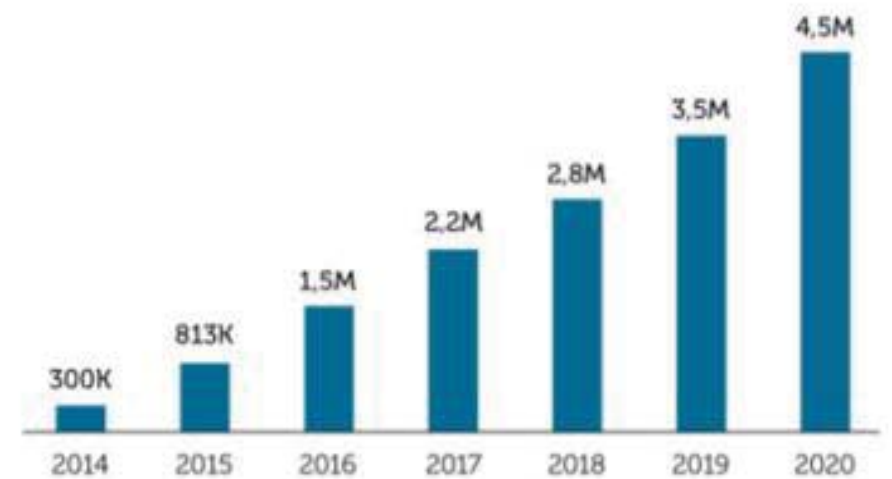

Fig. 6. Number of IoT developers 2014-2020 (Source: VisionMobile estimate 2014)

Whether these developers will be able to keep up with the demand is a major challenge. Systems need to be designed to accommodate and provide interoperability between existing machine-to-machine systems, different device manufacturers, and pre-existing service providers.

\section{IoT Challenges Faced By The Industry}

Despite the huge interest and demand for this technology and the efforts the industry is making, there are still lots of challenges and obstacles ahead that developers face towards the full IoT deployment. According to Harbor Research, an international research, technology and business development consulting firm, the biggest challenge IoT developers face is to enable a seamless interoperability between each IoT connection [4].

Another major challenge is to understand how the IoT possibilities fit into a working business model. Challenges are also present in the development phase of the applications themselves and vendors seem to have different views on the level of difficulties when it comes to development of these apps and according to them location-based and monitoring apps were listed as among the most difficult ones. In terms of best operating systems to work with IoT apps, vendors still seem to be divided and not fully synchronized. In this regard, Android is ahead with $29 \%$ of the respondents followed by Windows with $24 \%$ and as a platform, Java is the absolute winner with 55\% [4].

Other challenges are mainly to do with the legal and logistic difficulties to connect things and devices, provide the required intelligence at the edge and make use of the data for better decisions.

Legal and logistic difficulties can be regulatory requirements of different cities, harsh conditions, long distance between the devices etc.

Strict requirements for reliable, manageable and secure connected things as it is the case for smart grid is also a challenge.

\section{Issues Of IoT Technology}

Main concern that the industry and users have when it comes to IoT is the security issue. Security issue has not been addressed fully yet and it is inevitable that early IoT implementations will be insecure which will force the companies to enhance the security later on. According to HP Security Research, about $70 \%$ percent of Internet-connected devices are vulnerable to attacks caused by insecure Web interfaces and a lack of encryption [10]. IoT will be only as secure as the least secure device on the network, which means that enterprises will have to ensure that every part of any IoT they are involved with is secure and standards compliant.

Another big issue in IoT is privacy and data protection where extra efforts should be made to avoid security breaches that would result in heavy fines and penalties. Regardless of the security in place and given the huge data traffic travelling though IoT networks, enterprises will have specifically to add more security to data centre infrastructure that stores and processes the data from IoT devices. 
To address the security issue appropriately, a proper security is required at every level of the infrastructure, i.e. security at IoT endpoints, Gateways, Networks and on the Cloud.



Fig. 7. Main elements of an IoT infrastructure where security has to apply

\subsection{End Point Security:}

Security on this level should ensure the following

- Protect operational platform

- $\quad$ Protect existing and new applications

- Protect privacy of operators and data

\subsection{Gateway Security for IoT:}

- Should ensure secure connectivity of devices to Cloud

- Should manage security of existing devices

- Should manage the data flow and access of connected devices

- Should support the security of edge analytics

\subsection{Network Security}

- Should manage security across network

- Integrate security policies with Gateway and Cloud

- $\quad$ Provide intelligent and secure traffic shaping and prioritization

\subsection{Cloud and Data Centre Security}

- $\quad$ Support security and management for cloud

- $\quad$ Protect infrastructure platforms

- $\quad$ Secure data access between applications and operators

6.5 Other identified issues that IoT is faced with are as follows:

- $\quad$ Lack of access to Internet everywhere, though this is improving everyday

- Number of IoT sensors connected to Internet still not high enough to justify the full implementation

- Lack of standards, in particular lack of standardised communication protocols for the sensors to avoid data silos

- $\quad$ Lack of specified APIs to accommodate all sensor data types

- $\quad$ Powering a huge number of lower-power gadgets without batteries

\section{Standards Activities Around IoT}

Connecting everything and making these 'things' talking to each other is very complex and difficult task given the huge number of them and as such requires some order in this technology. Efforts to bring some order in IoT started in late 2013 and continued in 2014 and 2015 and most likely will continue till 2017.

One way to bring some order to this technology is through the development and adoption of open standards which involve agreements among the key players for a common IoT architecture and infrastructure, as shown in the figure below. 




Fig. 8. IoT Reference Model (Source: ITU-T)

This common architectural framework will enable the industry to clearly define relationships among the IoT's numerous vertical markets such as transportation, healthcare, and entertainment. This will prevent or minimize fragmentation of industry and vertical markets, will improve interoperability and enable the industry to build IoT ecosystems to leverage the power of those connected "things" in an efficient way.

In addition, standards enable companies to speed up their time to market and increase their market footprint.

The complexity of another structured relationship between IoT and other technologies is shown in figure 9 as part of a heterogeneous standards environment in IoT.

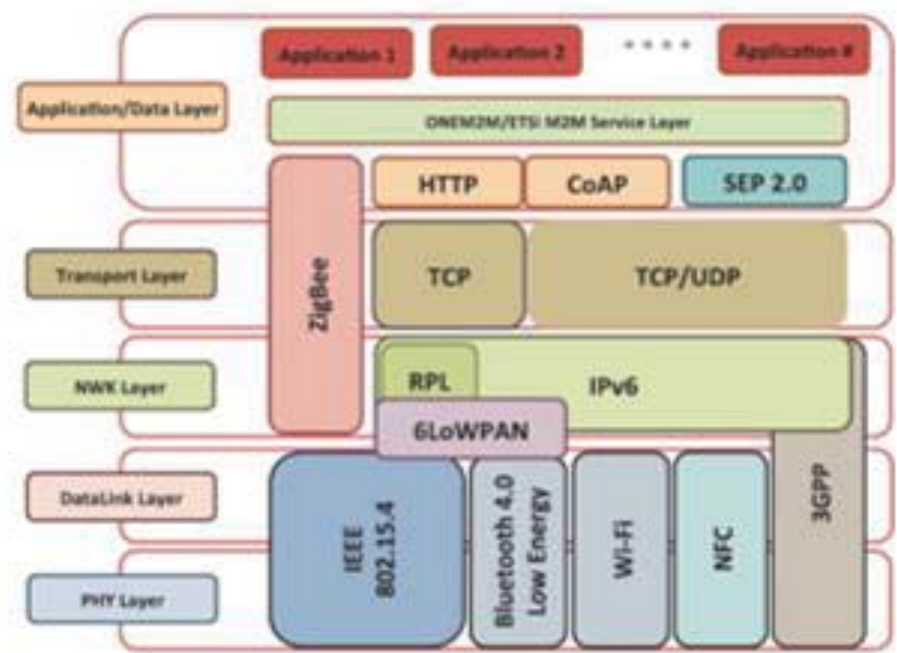

Fig. 9. Heterogeneous standards environment in IoT (Source: IoT Research EU)

Usually the pace of standards development is slower than the pace that vendors would like and therefore this makes vendors and the industry in general form de facto standards and not wait for formal standards bodies to complete the specifications which in the case of IoT will not finish before 
2017. This has become very common lately for various groups to form industry alliances where members accelerate the progress which leads to transferring to global standards. Cases like this in the past were ZigBee, HomePlug, Wi-Fi, IEEE 2030.5 etc., that started as industry alliances and became global standards at the end.

A number of standardization projects for IoT have been launched recently and their focus and goals could be summarized as following:

- Developing an architecture reference model to allow seamless integration of heterogeneous IoT technologies

- Develop technical specification for a common service layer to allow connectivity between IoT devices

- Develop an open universal IoT software framework

- Develop intelligent industrial automation

- Develop a thin interoperability layer to make data available for others to use it

- To provide an open source implementation

- Develop a standard interoperability architecture for information sharing

- Develop an open source protocol to run over 802.15.4 to support home products

- Develop a light-weight M2M protocol for remote management of M2M devices

A list of key IoT standardisation projects is given below, but there are many more that make the IoT race more crowded and more complex.

\begin{tabular}{|c|c|c|}
\hline $\begin{array}{ll}\text { AllSeen } & \text { Alliance } \\
\text { (December 2013) }\end{array}$ & $\begin{array}{l}\text { This alliance came up with } \\
\text { an open-source } \\
\text { framework, AllJoyn, } \\
\text { based on a technology } \\
\text { from Qualcomm [5] }\end{array}$ & $\begin{array}{l}\text { Qualcomm, Cisco } \\
\text { Systems, Panasonic and } \\
\text { some other electronics } \\
\text { vendors }\end{array}$ \\
\hline $\begin{array}{ll}\text { Open } & \text { Interconnect } \\
\text { Consortium } & \text { (OIC) (July } \\
2014) & \end{array}$ & $\begin{array}{l}\text { Aims to develop standards } \\
\text { and certification for } \\
\text { devices involved in IoT. } \\
\text { Developed an open source } \\
\text { software framework, } \\
\text { IoTivity that enables } \\
\text { seamless device-to-device } \\
\text { connectivity to address the } \\
\text { needs of IoT. }\end{array}$ & $\begin{array}{l}\text { Intel, Samsung, Dell, HP, } \\
\text { Lenovo, Broadcom etc. }\end{array}$ \\
\hline Thread Group (2014) & $\begin{array}{l}\text { Focuses on home security } \\
\text { and low-power features } \\
\text { that make it better for } \\
\text { connecting household } \\
\text { devices than other } \\
\text { technologies such as Wifi, } \\
\text { NFC, Bluetooth or } \\
\text { ZigBee. This protocol was } \\
\text { initially developed by } \\
\text { Nest, which was bought by } \\
\text { Google in } 2014 \text { [5]. }\end{array}$ & $\begin{array}{lr}\text { Google, } & \text { Samsung } \\
\text { Electronics, } & \text { ARM } \\
\text { Holdings, } & \text { Freescale } \\
\text { Semiconductor, } & \text { Silicon } \\
\text { Labs, Big Ass } & \text { Fans, and } \\
\text { Yale, a lock company }\end{array}$ \\
\hline $\begin{array}{ll}\text { Industrial } & \text { Internet } \\
\text { Consortium (IIC) (March } \\
\text { 2014) }\end{array}$ & $\begin{array}{l}\text { Aims to accelerate } \\
\text { development and adoption } \\
\text { of intelligent industrial } \\
\text { automation for public use } \\
\text { cases }\end{array}$ & $\begin{array}{l}\text { General Electric, Cisco } \\
\text { Systems, IBM, Intel and } \\
\text { AT\&T, } \\
\text { Samsung, Huawei }\end{array}$ \\
\hline
\end{tabular}




\begin{tabular}{|c|c|c|}
\hline IEEE P2413 (2014) & $\begin{array}{l}\text { Aims to create a standard } \\
\text { interoperability } \\
\text { architecture and define } \\
\text { commonly understood } \\
\text { data objects, for } \\
\text { information sharing across } \\
\text { IoT systems; } \\
\text { Standardization targeted } \\
\text { by } 2016 \text { [6] }\end{array}$ & $\begin{array}{l}\text { IEEE; collaborating with } \\
\text { oneM2M, ETSI and other } \\
\text { SDOs to evolve joint } \\
\text { standards }\end{array}$ \\
\hline $\begin{array}{l}\text { ITU-T SG20 on IoT and } \\
\text { its applications including } \\
\text { smart cities and } \\
\text { communities }\end{array}$ & $\begin{array}{l}\text { Aims to promote a unified } \\
\text { approach for development } \\
\text { of technical standards } \\
\text { including M2M (machine } \\
\text { to machine) and } \\
\text { ubiquitous sensor } \\
\text { networks enabling the } \\
\text { service providers globally } \\
\text { to offer services supported } \\
\text { by this technology [6]. }\end{array}$ & ITU-T members \\
\hline$\underline{\text { OMA LWM2M }}$ & $\begin{array}{l}\text { Working on a new Light- } \\
\text { weight M2M protocol } \\
\text { standard, for remote } \\
\text { management of M } 2 \mathrm{M} \\
\text { devices and related service } \\
\text { enablement }\end{array}$ & OMA members \\
\hline$\underline{\text { WiFi alliance }}$ & $\begin{array}{l}\text { Aims to develop } \\
\text { certifications that align } \\
\text { with Internet of Things } \\
\text { (IoT) needs and use cases } \\
\text { with multiple IoT industry } \\
\text { input. }\end{array}$ & WiFi Alliance members \\
\hline IoT-A (2010-2013) & $\begin{array}{lr}\text { Developed } & \text { an } \\
\text { architectural reference } \\
\text { model to allow seamless } \\
\text { integration } \\
\text { heterogeneous } \\
\text { technologies into a } \\
\text { coherent architecture to } \\
\text { realize 'Internet of Things' } \\
\text { rather than 'Intranet of } \\
\text { Things' }\end{array}$ & $\begin{array}{l}\text { ALU, Hitachi, IBM, NEC, } \\
\text { NXP, SAP, Siemens, and } \\
\text { universities - "Mission } \\
\text { Accomplished late 2013" }\end{array}$ \\
\hline oneM2M (2012) & $\begin{array}{l}\text { Aims to develop technical } \\
\text { specifications for a } \\
\text { common M2M Service } \\
\text { Layer to allow } \\
\text { connectivity between } \\
\text { devices and various M2M } \\
\text { applications, to realize } \\
\text { horizontally integrated } \\
\text { Internet-of-Things }\end{array}$ & $\begin{array}{l}\text { Leading ICT standards } \\
\text { bodies namely ETSI, } \\
\text { ARIB, TTC, ATIS, TIA, } \\
\text { CCSA and TTA }\end{array}$ \\
\hline
\end{tabular}


International Conference on Computer Science and Communication Engineering, Nov 2015

\begin{tabular}{|l|l|l|}
\hline$\underline{\text { HomePlug Alliance (Apr }}$ & $\begin{array}{l}\text { Aims to develop } \\
\text { technology specs for } \\
\text { powerline networking to } \\
\text { enable home connectivity }\end{array}$ & $\begin{array}{l}\text { AMD, 3Com, Cisco, Intel, } \\
\text { Intellon, Texas } \\
\text { Panasonic at al Motorola, }\end{array}$ \\
\hline$\underline{\text { HyperCat (May 2014) }}$ & $\begin{array}{l}\text { Aims to develop an open } \\
\text { specification for IoT that }\end{array}$ & $\begin{array}{l}\text { ARM, BT, IBM, Intel, } \\
\text { Living PlanIT, et al } \\
\text { will make data available in }\end{array}$ \\
& $\begin{array}{l}\text { a way that others could } \\
\text { make use of it, through a } \\
\text { thin interoperability layer. }\end{array}$ & \\
\hline
\end{tabular}

Table 1. Main IoT standardisation projects

\section{Use cases and implementation landscape}

There are so many practical applications and implementations of IoT in the real world and this section will only highlight some of them by putting them in main vertical areas of adoption [8]:

- Connected Wearable Devices

- Connected Cars

- Connected Homes

- Connected Cities, and

- Industrial Internet.

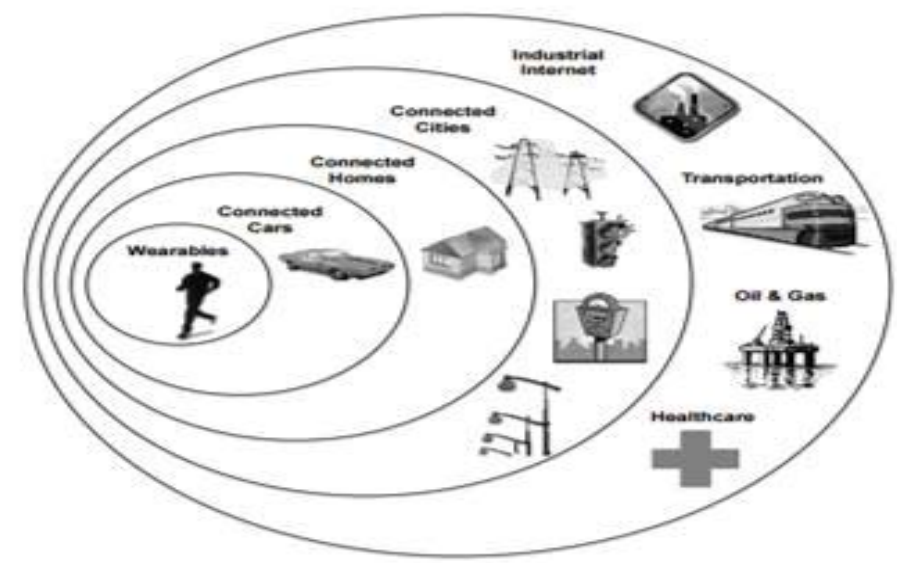

Fig. 10. The IoT landscape (Source: Goldman Sachs GIR)

\subsection{Connected Wearable Devices}

IoT has found wide application in eHealth industry through wearable devices that help to monitor the conditions of patients and also alert them on a potential risk. 


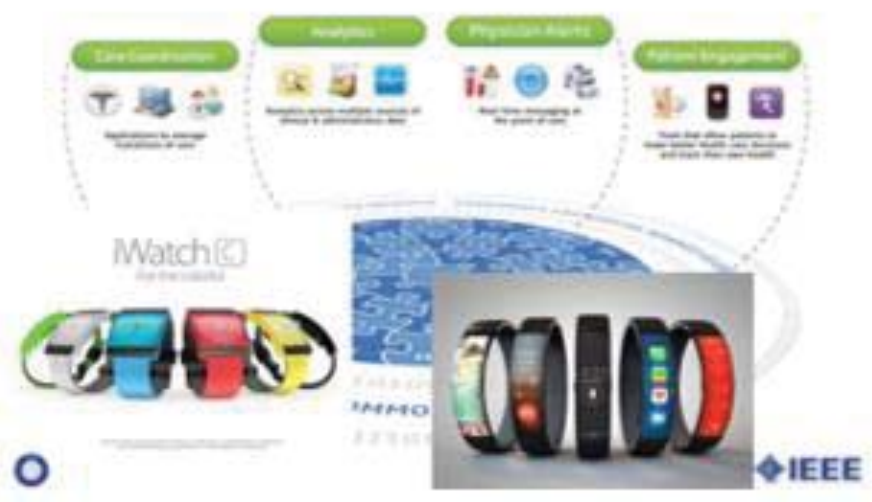

Fig. 11. Connected Wearables

\subsection{Connected cars}

Cars are expected to be a major element of Internet of Things, where about $20 \%$ of all vehicles, or a quarter of a billion cars on global roads, will have some sort of wireless network connection by 2020 [15]. Use of IoT and smart devices in connected cars will increase the fuel consumption efficiency.

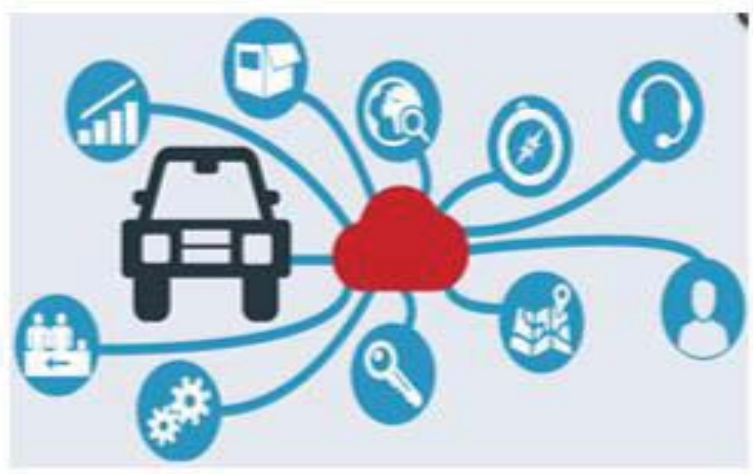

Fig. 12. Connected Cars

A study has shown that $13 \%$ of 2000 surveyed car owners would not consider buying a new car without internet access, while more than $25 \%$ of them have already prioritised connectivity over features such as engine power and fuel efficiency [15].

\subsection{Connected Homes}

Homes around the world are going to become smarter and more connected over the next five years, but the demand has not reached the full potential yet. 




Fig. 13. Connected Homes

The connected-home category will account for about $25 \%$ of shipments within the broader Internet of Things category in 2015, but this share will increase gradually to about $27 \%$ in 2019 according to BI Intelligence [15].

\subsection{Connected Cities}

Many cities in the world have started to leverage the IoT benefits to lower operating costs and increases efficiency through automation by incorporating new technologies and capabilities through software upgrades.

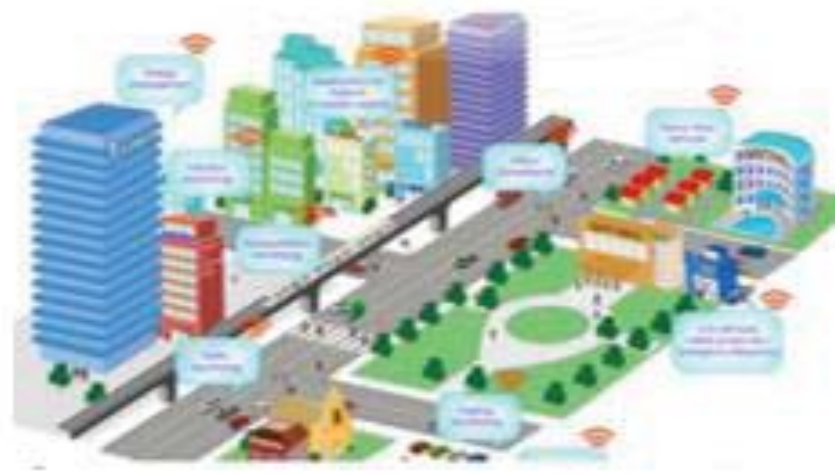

Fig. 14. Connected Cities

\subsection{Industrial Internet}

Industrial Internet refers to all devices, sensors, and software that enable connectivity between machines, i.e. physical 'thing'. Is not as broad as Internet of Things and is also known as M2M and which describes "machines" that use network resources to communicate with remote application infrastructure in order to monitor and control the machine itself or the surrounding environment. 


\section{Conclusion}

This paper analysed and looked at the IoT technology as a set of enabling technologies from the market, technology and standards perspective with the focus on drivers and hindering factors of the full IoT deployment. It was pointed out in this paper that IoT is changing the world and this transformation has already begun; this transformation will only continue to speed up.

From the market perspective, the key vertical markets were identified and the impact of IoT will have in this markets was analysed.

On the technology side, different technologies were mentioned and the importance of them for IoT was given. This paper also highlighted the importance of standardization for IoT, which provides interoperability, compatibility, reliability, and effective operations on a global scale. The emphasise was put on the crowd of IoT standards projects and on the list of key players in this race.

Challenges and issues were also analysed with the focus on the security of IoT and finally some implementation cases were described.

\section{References}

1. Asay, M.: Why The Internet Of Things Is Still Roadblocked, http://readwrite.com/2014/08/04/internet-of-things-obstacles-roadblocks, August 2014

2. van Rijmenam, M.: The Great Sensor-Era: Brontobytes Will Change Society, https://datafloq.com/read/the-great-sensor-era-brontobytes-will-change-socie/211, April 2015

3. Borne, K.: 14 Benefits and Forces That Are Driving The Internet of Things, https://www.mapr.com/blog/14-benefits-and-forces-are-driving-internet-things\#.VhWyw_lVikr, August 2014

4. Bolton, D.: Wanted: Developers To Build The Future Of The Internet Of Things, http://arc.applause.com/2015/06/26/internet-of-things-developer-opportunities, June 2015

5. Logvinov, O.: Open Standards Will Enable the IoT's Growth, http://electronicdesign.com/iot/openstandards-will-enable-iot-s-growth, September 2014

6. ITU-T Study Group 20: Internet of Things (IoT) and its applications including smart cities and communities (SC\&C), http://www.itu.int/en/ITU-T/about/groups/Pages/sg20.aspx, July 2015

7. Neagle, C.: A guide to the confusing Internet of Things standards world, http://www.networkworld.com/article/2456421/internet-of-things/a-guide-to-the-confusing-internetof-things-standards-world.html, July 2014

8. Ronzio, J.: How The "Internet of Things" Is Transforming the Landscape of Corporate Events, $\mathrm{http}$ //cramer.com/story/internet-of-things-transforming-the-landscape-of-events, 2015

9. Chamberlin, B.: Twenty Internet of Things trends to watch in 2015, http://ibmcai.com/2015/01/27/twenty-internet-of-things-trends-to-watch-in-2015, January 2015

10. Jankowski, S., Covello, J., Ritchie, J., Costa, D.:Goldman Sachs InternationalThe Internet of Things: Making sense of the next mega-trend, http://www.goldmansachs.com/ourthinking/pages/internet-of-things/iot-report.pdf, September 2014

11. Bingham, M.: IoT Perspectives, http://www.iotperspectives.com/connected-car.html, September 2014

12. Asay, M.: Maybe Asia-Pacific Developers Will Deliver The Internet Of Things, http://readwrite.com/2014/07/24/internet-of-things-asia-pacific-developers-to-the-rescue, July 2014

13. IoT-A: Introduction to the Architectural Reference Model for the Internet of Things, http://iotforum.org/wp-content/uploads/2014/09/120613-IoT-A-ARM-Book-Introduction-v7.pdf,

2015

14. Ramachandran B.: INTERNET OF THINGS - UNRAVELING TECHNOLOGY DEMANDS \& DEVELOPMENTS, $\quad$ https://connectedtechnbiz.wordpress.com/2014/10/17/iot-unravelingtechnology-demands-developments,

15. Tata Consultancy services: Companies using IoT technologies increased revenue by $16 \%$ in 2014 , http://sites.tcs.com/internet-of-things/key-findings/companies-using-iot-programs-increasedrevenue, 2014

16. IEEE Standards Association: Internet of Things (IoT) Ecosystem Study, https://standards.ieee.org/innovate/iot/iot_ecosystem_exec_summary.pdf, January 2015 